\title{
Chemical Composition and Antioxidant Activity of Rhododendron lepidotum Wall. ex D. Don, Essential Oil from Nepal
}

\author{
Dr. Susan Joshi ${ }^{*}$, Pawan Thapa ${ }^{2}$ \\ ${ }^{1}$ Associate Professor, Central Department of Chemistry, Tribhuvan University, Kirtipur, Kathmandu, Nepal \\ ${ }^{2}$ Central Department of Chemistry, Tribhuvan University, Kirtipur, Kathmandu, Nepal
}

*Corresponding Author: Dr. Susan Joshi, Associate Professor, Central Department of Chemistry, Tribhuvan University, Kirtipur, Kathmandu, Nepal

\begin{abstract}
The essential oil in the fresh leaves of Rhododendron lepidotum Wall. ex D. Don was isolated using Clevenger-type hydrodistillation apparatus and its chemical compositions were analyzed by GC-MS analytical method. A total numbers of 21 chemical constituents were identified and quantified occupying 96.68\% of total oil composition. The chemical constituent of Rhododendron oil composes of monoterpene hydrocarbons, oxygenated montoterpines and sesquiterpine hydrocarbons. The major chemical constituents were $\alpha$-pinene $(39.35 \%)$ and $\beta$-pinene $(13.82 \%)$ along with trans-caryophyllene $(9.79 \%)$, $\delta$-cadinene $(9.4 \%)$, $\beta$-myrcene (7.25\%) and $\alpha$-amorphene (3.77\%). The antioxidant activity of Rhododendron lepidotum oil was studied based on DPPH (1,1-diphenyl-2-picryl-hydrazyl) radical scavenging activity by finding $I C_{50}$ value and comparing its $I C_{5}$ o value with standard ascorbic acid. $I C_{5}$ o value associated with it was $12.22 \mu \mathrm{g} / \mathrm{ml}$ which is nearly closer with standard ascorbic acid $(4.42 \mu \mathrm{g} / \mathrm{ml})$ indicating that the fresh leaves of Rhododendron lepidotum essential oil shows good potential antioxidant activities.
\end{abstract}

Keywords:Rhododendron lepidotum, GC-MS, essential oil, monoterpene, sesquiterpene, antioxidant.

\section{INTRODUCTION}

Rhododendrons are of the genus Rhododendron that belonging to the family Ericaceae. It is represented by about 1025 species in the world, mostly concentrated in the Himalayan region of Nepal, and the temperate regions of Northern hemisphere especially in Sino-Himalayas (Eastern Himalayas and Western China). Besides this main centre, the Rhododendrons have further proliferated towards southern and northeastern China, Japan, Myanmar, Thailand, Malaysia, Indonesia, Philippines and New Guinea. A few species are also reported from Afghanistan, Australia Pakistan, southern parts of Europe and northern parts of America [1]. In Nepal, this genus comprises 32 species most of these are distributed at the altitude ranging from $1500-5000 \mathrm{~m}$. This genus has long been used as folk medicine in Nepal and other countries of the world. A few members of this genus such as $R$. ponticum and $R$. lustem contained grayanine type tetracyclic diterpenes which are known to be toxic to common livestock such as cattle. But a large members of this genus contained bioactive chemical constituents such as essential oils, ursolic acid, oleanolic acids, phenol, coumarins, flavonoids, etc these are important for human being [2].

Rhododendronlepidotum is a highly variable shrub, growing up to 2 meters tall with white, yellow, pink or purple flower and Its leaves are elliptic with upper surface dark green and lower surface contained large brownish scales. The aerial parts of this plant (leaves, stem and flower) are known for their essential oils, which is known as Bhale Sunpati oil in Nepal. They are valuable natural products and are procured as raw materials in many fields, such as perfumes, cosmetics, aromatherapy, spices and nutrition [3]. The higher composition of pinene in most essential oil has proved for their greater antibacterial and antifungal activities while the limonene has been found to be effective against tumor cell line [4]. The essential oil derived from the leaves of Rhododendron lepidotum has recently attracted attention of the researchers for its medicinal and perfumery importance as ingredient in perfume and as incense due to great valuable scope [5]. Oxidative stress through treatment with antioxidants is an effective strategy for reducing neurological complications like Parkinson's disease and Alzheimer type dementia. With the depletion of immune system and natural antioxidants in different maladies, consuming antioxidants as free radical scavengers may be necessary [6]. An easy, 
rapid and sensitive method for the antioxidant screening of plant extracts is free radical scavenging assay using 1,1-diphenyl-2-picryl hydrazyl (DPPH) stable radical spectrophotometrically.The information on the secondary metabolites and bioactivities of Rhododendron lepidotumare scarce inspite the few aforementioned data on the chemistry and bioactivities. Therefore the present study was intended to explore chemical compositionand antioxidant activities of fresh leaves of Rhododendron lepidotum essential oil.

\section{Material AND Method}

\section{A. Plant Material}

The fresh leaves of Rhododendron lepidotum, were collected in the month of November 2012 from Simbhanjhyang, Makwanpur district of Nepal which is located in $27 \mathrm{O} 35^{\prime} 26^{\prime}$ " N and $85 \mathrm{O} 05^{\prime} 04$ " E at about $2500 \mathrm{~m}$ above sea level) during November 2012. The plant material was identified by Senior Botanist K. K. Shrestha of Central Department of Botany, Tribhuvan University, Kirtipur, Nepal.

\section{B. Extraction of Essential Oils}

The essential oils in the fresh leaves of Rhododendron lepidotum was extracted by hydrodistillation method using Clevenger-type distillation apparatus. These leaves sample (100 gm) were cut into small pieces and kept into round bottom flask along with distilled water. The content of the flask was heated in heating mantle at boiling temperature and the process was allowed to continue for 6 hours followed by standing for one hour at room temperature. The Rhododendron lepidotum oil obtained was dried using anhydrous sodium sulphate and stored in airtight reagent bottle at $4^{0} \mathrm{C}$ for further use.

\section{Gas Chromatography and Mass Spectral Analysis}

The essential oil obtained was analyzed by Gas Chromatography- Mass spectrometry using a Shimadzu gas chromatography mass spectrometer QP-2010, Japan operated in the electron impact (EI) mode (electron energy $70 \mathrm{eV}$ ) and ion source temperature $200^{\circ} \mathrm{C}$ under the following conditions: injection volume $1 \mu \mathrm{L}$ with split ratio 1:90; Helium as carrier gas at $1 \mathrm{ml} / \mathrm{min}$ constant flow mode, injector temperature $280^{\circ} \mathrm{C}$, oven temperature $40^{\circ} \mathrm{C}$ to $250^{\circ} \mathrm{C}$ at the rate of $7^{\circ} \mathrm{C} / \mathrm{min}$. Mass spectra were recorded in the scan range between 35-500 atomic mass units. Identification of the chemical constituents from Rhododendron oils was based on their retention indices determined by reference and comparison of their mass spectral fragmentation patterns using previously reported references and using NIST 05, WILEY and SZTERP libraries.

\section{1, 1-diphenyl-2-picryl-hydrazyl (DPPH) Radcial Scavenging Method}

The ability of essential oil of Rhododendron lepidotum leaves to scavenge 1, 1-diphenyl-2-picrylhydrazyl (DPPH) free radicals was estimated as previously described elsewhere [7] (Rohani et al., 2009). The percentage of radical scavenging activity was calculated using the following formula:

$$
\frac{\text { Radical scavenging }(\%)=\left[\left(\mathrm{A}_{0}-\mathrm{A}_{1}\right) / \mathrm{A}_{0} \times 100\right]}{\text { Identify applicable sponsor/s here. If no sponsors, delete this text box (sponsors). }}
$$

Where,

$\mathrm{A}_{0}=$ absorbance of control

$\mathrm{A}_{1}=$ absorbance of the sample

Ascorbic acid was used as a reference standard in different concentrations $(0.81,1.625,3.125,6.25$, 12.5 and $25 \mu \mathrm{g} / \mathrm{ml}$ ). The amount of $100 \mathrm{mg}$ of ascorbic acid was dissolved in $50 \mathrm{ml}$ methanol. The standard solution was taken as $100 \mu \mathrm{g} / \mathrm{ml}$ and below while the analysis for oil included the concentrations $(10,5,2.5,1.25,0.625$ and $0.3125 \mu \mathrm{g} / \mathrm{ml})$ that were added to $2 \mathrm{ml}$ of DPPH. The $50 \%$ inhibitory concentration value $\left(\mathrm{IC}_{5} 0\right)$ is indicated as the effective concentration of the sample that is required to scavenge $50 \%$ of the $\mathrm{DPPH}$ free radicals. $\mathrm{IC}_{5} 0$ values were calculated using the dose inhibition curve in linear range by plotting the essential oil concentration versus the corresponding scavenging effect.

\section{RESULTS AND DISCUSSION}

\section{A. Chemical Composition of Essential Oil}

The essential oil present in the fresh leaves of Rhod8dendron lepidotum was obtained by hydro distillation method using Clevenger-type distillation apparatus. The percentage amount of oil obtained 
was quantified and the result of the observation was found to be $2.19 \%$ by mass. The essential oil extracted from the species of Rhododendron in consideration was colorless, slightly viscous but non sticky with sweet balsamic odor. The fresh leaves of Rhododendron lepidotum essential oil composition are given in Table 1.

The GC/MS analysis of the Rhododendron lepidotum essential oil revealed that most of the compounds were monoterpenes and sesquiterpenes. Twenty four peaks were observed in the gas chromatogram out of which twenty one different compounds could be identified and quantified occupying $96.68 \%$ of total oil composition. Among these identified compounds, four were monoterpene hydrocarbons, one was alcohol derivative of monoterpene ( $\alpha$-Terpeneol), thirteen were sesquiterpenes, two were alcohol derivative of sesquiterpene ( $\tau$-Cadinol and $\alpha$-Cadinol) and the remaining one was epoxy derivative (Caryophyllene oxide). Two major constituents among monoterpenes were $\alpha$-pinene (39.35\%) and $\beta$ pinene $(13.82 \%)$, while the major constituent representing sesquiterpene was trans-caryophyllene (9.79\%). The present study revealed that chemical constituents and percentages are different from previously published work of Kasmir, India. The Indian origin essential oil revealed the principal components $\alpha$-pinene $(54.4 \%)$ and $\beta$-pinene $(12.5 \%)$ as major composition together with other constituents limonene $(6.5 \%)$, and $\alpha$-humulene $(4.2 \%)$ bornyl acetate $(2.8 \%)$, terpinene $(2.2 \%)$ [8]. This chemical constituent found was however different from the studies on other Rhododendron species: the main components of $R$. nivale essential oil were $\delta$-cadinene and $\alpha$-cadinol [9]. Furthermore, studies on essential oils from leaves of $R$. dauricum and $R$. aureum revealed that the major chemical constituents were trans-caryophyllene and calarene, respectively [10]. And $\beta$-pinene, camphene and $\delta$-3-carene were the major constituents of the oil of R. mucronulatum [11].

\section{B. DPPH Scavenging Activity}

The fresh The antioxidant activity possessed by essential oil of the plant species was studied based on Rohani et.al. The antioxidant potential of essential oil was analyzed on the basis of $\mathrm{IC}_{50}$ value correlating with that of standard ascorbic acid. The following Figure 2 represents different $\%$ inhibition with different concentration of ascorbic acid and essential oil. $\mathrm{IC}_{50}$ value of essential oil of Rhododendron lepidotum was compared with that of standard ascorbic acid from the given curve in Figure 3. Analysis on antioxidant activity of essential oil derived from fresh leaves of Rhododendron lepidotum was done from its $\mathrm{IC}_{50}$ value. The result revealed that essential oil from fresh leaves of Rhododendron lepidotum had shown good potential antioxidant activity since its $\mathrm{IC}_{50}$ value was $12.22 \mu \mathrm{g} / \mathrm{ml}$ which is closer to $\mathrm{IC}_{50}$ value of that of standard ascorbic acid $(4.42 \mu \mathrm{g} / \mathrm{ml})$. The DPPH radical scavenging activity of essential oil of fresh leaves of Rhododendron.

Table1.Chemical Composition of the Essential Oil of the Fresh Leaves OF R lepidotum from Simbhanjany, Nepal

\begin{tabular}{|c|c|c|c|c|c|}
\hline S.N. & Compounds & MW & $\mathbf{R} \mathbf{t}$ & Area \% & Identification Method \\
\hline 1 & $\alpha$-Pinene & 136 & 7.683 & 39.35 & RI, MS \\
\hline 2 & $\beta$-Pinene & 136 & 8.658 & 13.82 & RI, MS \\
\hline 3 & $\beta$-Myrcene & 136 & 8.883 & 7.25 & RI, MS \\
\hline 4 & Limonene & 136 & 9.783 & 1.59 & RI, MS \\
\hline 5 & $\alpha$ - Terpeneol & 154 & 13.358 & 0.53 & RI, MS \\
\hline 6 & $\alpha$-Copaene & 204 & 17.1 & 0.87 & RI, MS \\
\hline 7 & $\beta$ - Bourbonene & 204 & 17.3 & 0.83 & RI, MS \\
\hline 8 & trans-Caryophyllene & 204 & 17.975 & 9.79 & RI, MS \\
\hline 9 & $\beta$-Farnesene & 204 & 18.408 & 0.84 & RI, MS \\
\hline 10 & $\alpha$-Humulene & 204 & 18.6 & 0.82 & RI, MS \\
\hline 11 & $\delta$-Cadinene & 204 & 18.9 & 0.51 & RI, MS \\
\hline 12 & $\alpha$-Amorphene & 204 & 18.95 & 2.53 & RI, MS \\
\hline 13 & Germacrene-D & 204 & 19.083 & 0.88 & RI, MS \\
\hline 14 & $\alpha$-Murolene & 204 & 19.358 & 1.77 & RI, MS \\
\hline 15 & $\alpha$-Amorphene & 204 & 19.633 & 3.77 & RI, MS \\
\hline 16 & $\delta$-Cadinene & 204 & 19.75 & 9.4 & RI, MS \\
\hline 17 & $\alpha$-Cadinene & 204 & 20.033 & 0.73 & RI, MS \\
\hline 18 & Caryophyllene oxide & 220 & 20.917 & 0.56 & RI, MS \\
\hline 19 & $\tau$-Cadinol & 222 & 21.792 & 1.58 & RI, MS \\
\hline 20 & Sativene & 204 & 21.892 & 1.26 & RI, MS \\
\hline 21 & $\alpha$-Cadinol & 222 & 22.017 & 1.32 & RI, MS \\
\hline
\end{tabular}


Chemical Composition and Antioxidant Activity of Rhododendron lepidotum Wall. ex D. Don, Essential Oil from Nepal

The constituents are presented based on retention time (Rt),molecular weight $(M W)$,retention Indexes(RI) and Mass Spectrum (MS).

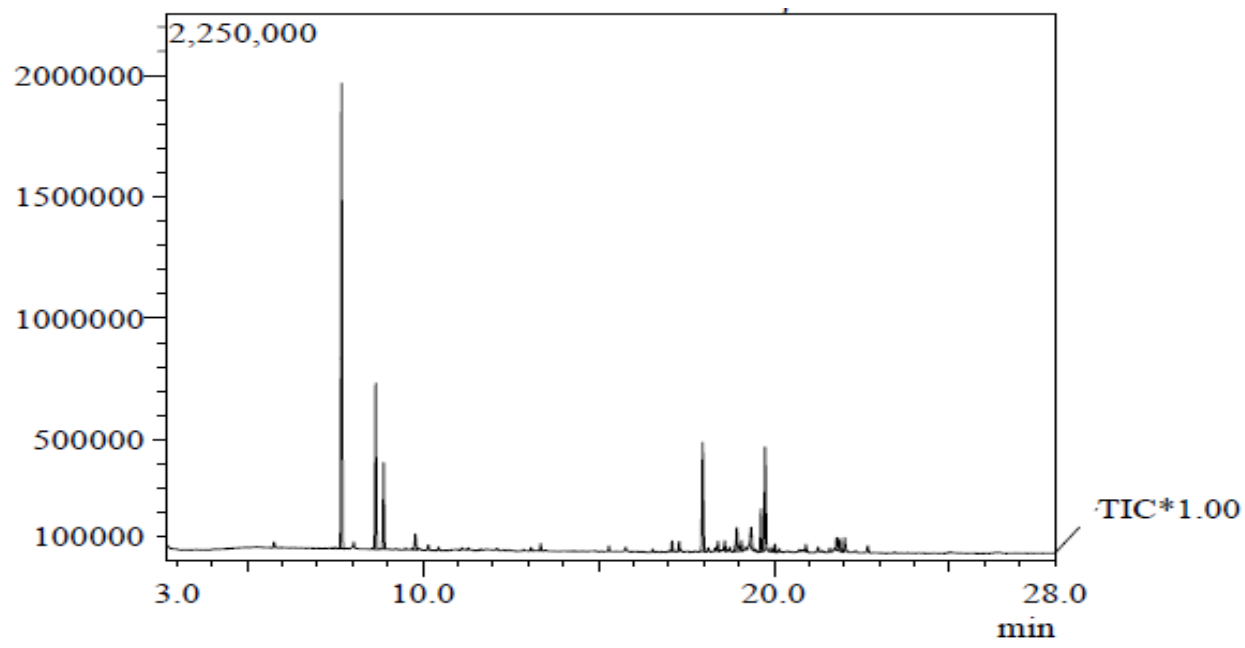

Figure1.Gas Chromatogram of essential oil fresh leaves of Rhododendron lepidotum

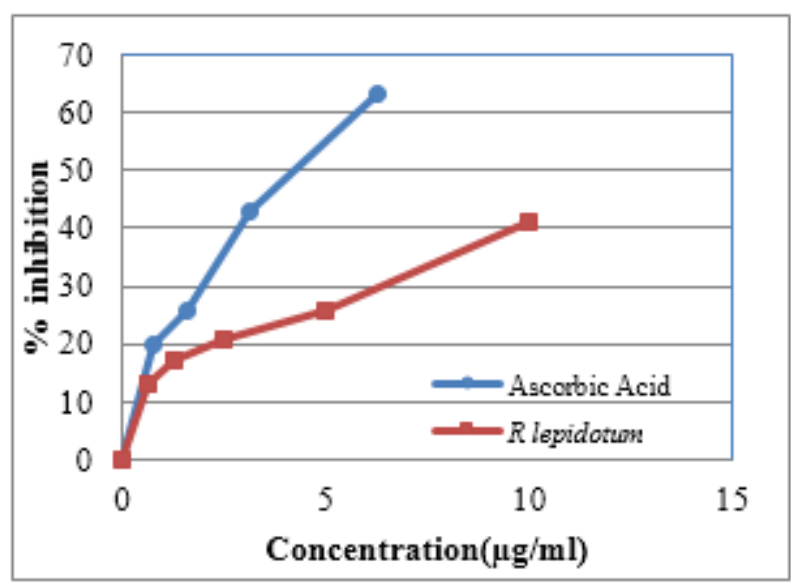

Figure2.DPPH scavenging activity of essential oil of Rhododendron lepidotum and standard ascorbic acid at different concentration

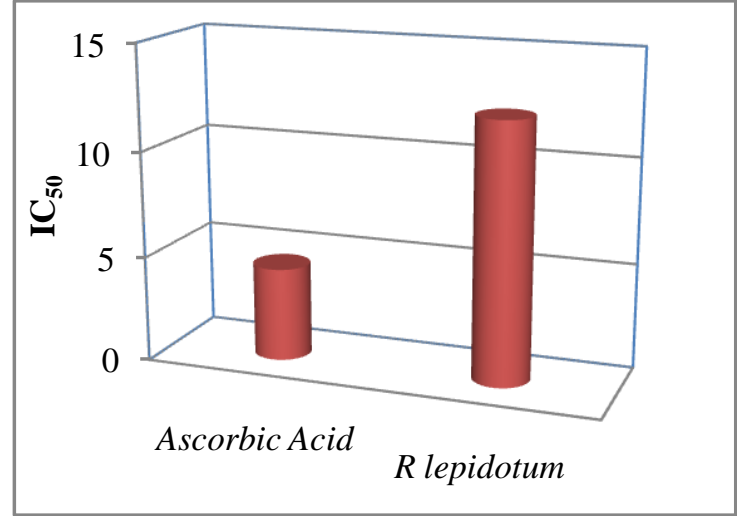

Figure3. Comparison of $I C_{5}$ o value of Essential oil with Ascorbic acid

lepidotum collected from Simbhanjhyang, of Makwanpur district of Nepal has not been reported earlier. The potential antioxidant activity of this essential oil attributed to synergistic effect of the complex chemical constitutions present in natural product either in major and minor amounts.

\section{CONCLUSION}

To the best of out knowledge, this paper is deemed to be the first to have reported the chemical constituents and antioxidant activity of the essential ${ }^{1}$ il from the fresh leaves of Rhododendron lepidotum. The essential oil showed potential antioxidant activity since the $\mathrm{IC}_{5} 0_{0}(12.22 \mu \mathrm{g} / \mathrm{ml})$ value 
of the oil was slightly higher than that of standard ascorbic acid whose $\mathrm{IC}_{5} \quad$ was found to be 4.42 $\mu \mathrm{g} / \mathrm{ml}$. Since, there is a greater demand for $\alpha$-pinene and $\beta$-pinene in perfumery industry, the appreciable amount of $\alpha$ - pinene and $\beta$-pinene in the essential oil of this plant may find extensive applications in such areas.

\section{ACKNOWLEDGMENT}

We are very thankful to University Grant Commission (UGC), Kathmandu, Nepal for a financial support to carry out this research work. Our appreciation is conveyed to Central Department of Chemistry, T.U, Kirtipur for providing laboratory facilities. Special thank goes to Krishna Subedi, Central Department of Biotechnology, T.U., Kirtipur for helping us with antioxidant analysis.

\section{REFERENCES}

[1] Chamberlain, D. F., Hyam, R., Argent, G., Fairweather, G. and Walter, K. S., "The genus Rhododendron: Its classification \& synonymy," Royal Botanical Garden, Edinburgh 1996.

[2] Bhattarai, K., Shrestha, T.M., Bajracharya,R., Jain, S.C. and Lamichhane,J,"Biological Activities of Three Different Medicinal Plants from Himalayan Region of Nepal," Nepal Journal of Science andTechnology, vol. 11, pp. 139-146,2010.

[3] Buchbauer, G, "The detailed analysis of essential oils leads to the understanding of their properties". Perfume Flavourist vol. 25, pp. 64-67, 2000.

[4] Buchbauer, G.,"On the biological properties of fragrance compounds and essential oils," Wien Med.Wonchenschr vol. 154, pp. 539-547, 2004.

[5] The Wealth of India, "A Dictionary of Indian Raw Materials and Industrial Products," New Delhi vol. 9, pp. 18, 2003.

[6] Halliwell, B.,"Free radicals, Antioxidants and Human Disease: Curiosity, Cause, or Consequence,"Lancet Vol. 344, pp. 721- 724, 1994.

[7] Yassa.N, Masoomi, F., Rankoushi. R, S. E. and Hadjiakhoondi, A., "Chemical Composition and Antioxidant activity of the Extract and Essential oil of Rosa damascene from Iran,"Population of Guilan, DARU vol. 17, pp. 3,2009.

[8] Manzoor, A. R., Shakeel, U. R., Shahnawaz, N. S., Abdul S. S., Fauzia, M. and Mushtaq, A. Q.,"Chemical Composition of the Essential Oil of Rhododendron lepidotum Wall ex D. Don Growing in Kashmir Himalayas,” Journal of Essential Oil Research vol. 23(6), pp. 25-28, 2011.

[9] Hao, L. \& Xiao-yang, C., "Analysis on the chemical composition of essential oil in Rhododendron nivale from Tibet," Huanan Nongye Daxue Xuebao,vol. 29, pp. 117-118, 2008.

[10] Olennikov, D.N., Dudareva, L.V., Osipenko, S.N. and Penzina, T.A. ,"Chemical Composition of Essential oils from leaves of Rhododendron dauricum and R. aureum," Chem. Nat. Comp. , vol. 45, pp. 450-452, 2009.

[11] Yu-Hwa, P. and Songmun, K.,"Composition and Cytotoxicity of Essential oil from Korean Rhododendron (Rhododendron mucronulatum Turcz. Var. ciliatum Nakai)," Han'guk Eungyong Sangmyong Hwahakhoeji, vol: 51, pp. 233-237, 2008.

Citation: S. Joshi \& Pawan Thapa, "Chemical Composition and Antioxidant Activity of Rhododendron lepidotum Wall. ex D. Don, Essential Oil from Nepal", International Journal of Advanced Research in Chemical Science (IJARCS), vol. 5, no. 8, pp. 14-18, 2018. http://dx.doi.org/10.20431/2349-0403.0508003

Copyright: (0) 2018 Authors. This is an open-access article distributed under the terms of the Creative Commons Attribution License, which permits unrestricted use, distribution, and reproduction in any medium, provided the original author and source are credited. 